\title{
SCIDiC
}

\author{
International Journal of Dentistry and Oral Science (IJDOS) \\ ISSN: 2377-8075
}

\section{Evaluation of Mandibular Second Premolars in a Kashmiri Population using Digital Radiography}

Research Article

\author{
Mushtaq $\mathrm{M}^{1 *}$, Khan $\mathrm{FY}^{2}$
}

${ }^{1}$ Department of Conservative Dentistry and Endodontics, Government Dental College and Hospital Srinagar, Kashmir, India.

${ }^{2}$ Department of Periodontics and Oral Implantology, Government Dental College and Hospital Srinagar, Kashmir, India.

\section{Abstract}

\begin{abstract}
Mandibular premolars are known for having variations in root canal anatomy, Endodontic and periodontal success of such anatomical variations requires the clinician to be aware of their clinical and radiographic anatomy. This study was done to evaluate the mandibular second premolars in a kashmiri population using routine digital radiography.
\end{abstract}

Keywords: Anatomical Variation; Endodontic Treatment; Mandibular Second Premolar.

\section{Introduction}

Any successful dental treatment depends on adequate knowledge of dental anatomy [1,2] especially in anatomical variations [3]. The dental Clinician should always see for any aberration in root canal anatomy for a successful dental treatment. Mandibular premolars are known for variation in their internal and external morphology due to the possible presence of more than one root canal [7-11]. An incidence of $0.4 \%$ of mandibular second premolars with three root canals has been reported $[11,12]$. There have been reports of mandibular second premolar with 3, 4 and even 5 root canals $[9,13,14]$. Anatomical variations of the pulp cavity have been diagnosed by computed tomography [15] and optical microscopy [16], but a thorough radiographic interpreatation can diagnose such cases most of the time. There are no studies reported in the literature evaluating mandibular second premolars in a kashmiri population. The study was done to evaluate mandibular second premolars in a kashmiri population using routine digital radiography.

\section{Materials and Methods}

The study was conducted jointly in the departments of periodontics and conservative dentistry and endodontics, government Dental college srinagar. A total of 400 patients were included in the study. The criteria of patients for inclusion in the study were:

\author{
a)Age $>18$ years \\ b) Presence of atleast one mandibular second premolar in the \\ mouth \\ c) kashmiri origin patients
}

800 mandibular second premolars were evaluated using full mouth digital radiographs (Schick technologies, NY, USA) using mesial angulation of 20-30 degree. The digital radiographs were evaluated by atleast two observers. The study was approved by institutional review board. The majority of 792 mandibular second premolars had one root, seven mandibular second premolars had two roots and only one mandibular second premolar had 3 roots and root canals (confirmed after successful root canal treatment (Figures 1,2). There was no significant difference regarding the occurance of 3 rooted mandibular second premolar between males and females.

\section{Results and Statistical Analysis}

The preoperative radiographic estimation in 800 mandibular second premolars was carried out during the period of the study. Pre-operative radiographic estimation revealed that 99 percent of the maxillary first premolars had one canal and 0.875 percent had two canals and only a rare 0.25 percent had 3 separate roots and canals, Table 1.

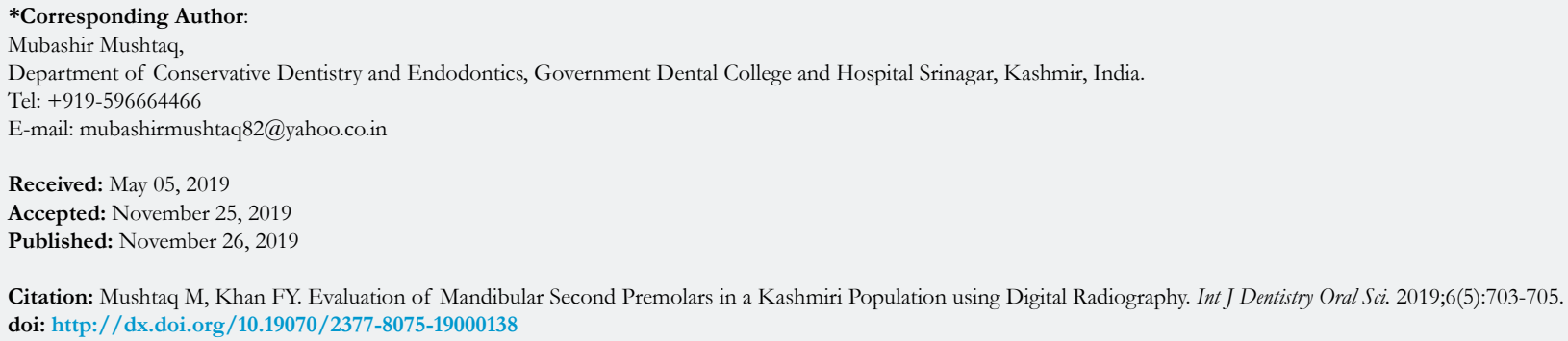

Copyright: Mushtaq $\mathbf{M}^{\circ}$ 2019. This is an open-access article distributed under the terms of the Creative Commons Attribution License, which permits unrestricted use, distribution and reproduction in any medium, provided the original author and source are credited. 
Figure 1.

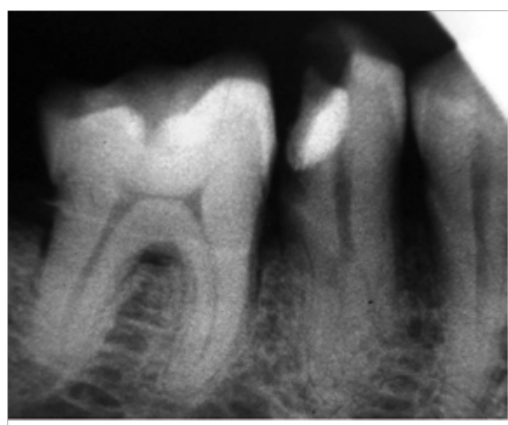

Figure 2.

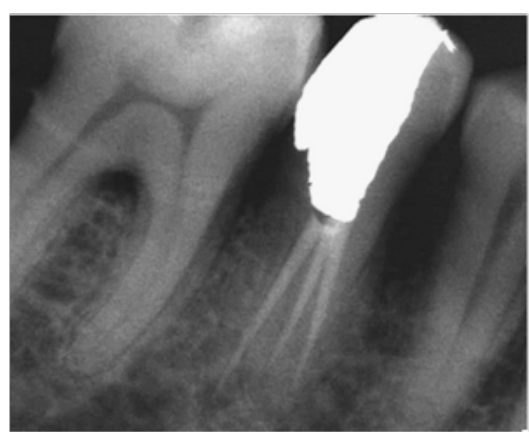

Table 1.

\begin{tabular}{|c|c|c|c|c|c|c|}
\hline \multirow{2}{*}{ Teeth } & \multicolumn{2}{|c|}{1 canal } & \multicolumn{2}{c|}{2 canals } & \multicolumn{2}{c|}{3 canals } \\
\cline { 2 - 7 } & No & $\mathbf{( \% )}$ & No & $\mathbf{( \% )}$ & No & $\mathbf{( \% )}$ \\
\hline Mandibular second premolar & 792 & 99 & 7 & 0.875 & 1 & 0.125 \\
\hline
\end{tabular}

\section{Discussion}

The morphological variations of the mandibular second premolar makes this tooth as one of the enigmas for endodontic and periodontal treatment. Certain authors have proposed that the Mandibular premolars pose the clinician with greatest difficulty of all teeth to treat [4]. A study reported the failure rate of nonsurgical root canal treatment in all teeth showing the highest for the Mandibular first premolar at $11.45 \%$ [17]. The reasons for this treatment outcome being he numerous variations in the root canal morphology and difficult access to a second canal. Mandibular second premolar shows a variable root canal anatomy $[16,18]$. A study that included first and second premolars has reported a $27.8 \%$ incidence of mandibular premolars with more than one canal [19]. A radiographic study showed that $15.7 \%$ of patients had atleast one mandibular first premolar with either a divided canal or a root $[20] .7 \%$ of mandibular second premolars had multiple canals in this study. The second canal in a mandibular second premola, is usually fine and branched towards the lingual surface in the middle or the apical third of the main canal. An ethnic study showed differences between African American and Caucasian patients [21], with the African American group showing higher percentage $(7.8 \%)$ than the Caucasian group $(2.8 \%)$. A Turkish study showed an incidence of two or more canals in $43 \%$ of the male patients and $15 \%$ of the female patients [22]. Preoperative diagnostic radiographs are employed to identify anatomical alterations of the root canal system. Careful analysis of the pulp chamber can also help in identifying these internal variations and their exact location $[16,23]$. Thorough radiographic examination of the periodontal ligament space could help in identifying an extra root or canal. Indeed, in the present study, it can be noticed a sudden change of the radiopacity of the canal space (Figure 1). The radiolucent space uniformly disappears from the pulp chamber, suggesting a possible presence of an additional canal $[11,12$, 15]. Furthermore the access cavities in these teeth are very small, hence impeding the visualization of the area. A modified endodontic access is needed to serach for such extra root canals [24]. In these cases, in order to better visualize the pulp chamber, the access cavity should have divergent walls to the occlusal face The success of any dental treatment depends on thorough knowledge of root canal anatomy. The other factoresz include recent instruments and the knowledge to use these instruments effectively. Teeth with extra roots and/or canals pose a particular challenge. This study evaluated the mandibular second premolar and its variations in a kashmiri population using digital radiography some guidelines that can help produce successful treatment outcomes.

\section{References}

[1]. Krasner P, Rankow HJ. Anatomy of the pulp-chamber floor. J Endodont. 2004 Jan 1;30(1):5-16.

[2]. Rodig T, Hulsmann M. Diagnosis and root canal treatment of a mandibular second premolar with three root canals. Int Endod J. 2003 Dec;36(12):9129.Pubmed PMID: 14689961.

[3]. Sikri VK, Sikri P. Mandibular premolars: aberrations in pulp space morphology. Indian J Dent Res. 1994 Jan-Mar;5(1):9-14. Pubmed PMID: 9495145.

[4]. Slowey RR. Root canal anatomy: road map to successful endodontics. Dent Clin North Am. 1979 Oct;23(4):555-73. Pubmed PMID: 294389.

[5]. Weine FS. Non surgical re-treatment of endodontic failures. Compend Cont Educ Dent. 1995 Mar ;16(3):326-335. Pubmed PMID: 8935002.

[6]. Hoen MM, Pink FE. Contemporary endodontic retreatments: an analysis 
based on clinical treatment findings. J Endod.2002 Dec;28(12) :834-836. Pubmed PMID: 12489654.

[7]. England Jr MC, Hartwell GR, Lance JR. Detection and treatment of multiple canals in mandibular premolars. J Endod. 1991 Apr;17(4):174-8. Pubmed PMID: 1940736.

[8]. Baisden MF, Kulild JC, Weller RN. Root canal configuration of the mandibular first premolar. J Endod. 1992 Oct;18(10):505-8. Pubmed PMID: 1289476.

[9]. Macri E, Zmener O. Five canals in a mandibular second premolar. J Endod. 2000 May;26(5):304-5. Pubmed PMID: 11199743.

[10]. Prakash R, Nandini S, Suma Ballal, Kumar Sowmya N, Kandaswamy D. Two-rooted mandibular second premolars: case report and survey. Indian J Dent Res. 2008 Jan-Mar;19(1):70-3. Pubmed PMID: 18245928.

[11]. Almeida-Gomes F, Sousa BC, Santos RA. Unusual anatomy of mandibular premolars. Aust Endod J. 2006 Apr;32(1):43-5. Pubmed PMID: 16603046.

[12]. Vertucci FJ. Root canal morphology of mandibular premolars. J Am Dent Assoc. 1978 Jul;97(1):47-50. Pubmed PMID: 277575.

[13]. Cleghorn BM, Christie WH, Dong CC. Anomalous Mandibularpremolars: a mandibular first premolar with three rootsand a mandibular second premolar with a C- shaped canal. system. Int Endod J. 2008 Nov;41(11):100514. Pubmed PMID: 19133090

[14]. Al-Fouzan KS. The microscopic diagnosis and treatment of a mandibular second premolar with four canals. Int Endod J. 2001 Jul;34(5):406-10. Pubmed PMID: 11482725.

[15]. Cleghorn BM, Christie WH, Dong CC. The root and root canal morphology of the human mandibular first premolar: a literature review. J Endod.
2007 May;33(5):509-16. Pubmed PMID: 17437863.

[16]. De Moor RJG, Calberson FLG. Root canal treatment in a Mandibular second Premolar with three root canals. J Endod. 2005 Apr; 31(4):310-313.

[17]. Ingle JI, Bakland LK, Endodontics. 5th ed. Hamilton: BC Decker Inc; 2002.

[18]. Nallapati S. Three canal mandibular first and second premolars: a treatment Approach. A case report. J Endod. 2005 Jun;31(6):474-6. Pubmed PMID: 15917692.

[19]. Kartal N, Yanikoglu F. The incidence of Mandibular premolars with more than one root canal in a Turkish population. J Marmara Univ Dent Fac. 1992 Sep;1(3):203-10. Pubmed PMID: 1308778.

[20]. Serman NJ, Hasselgren G. The radiographic incidence of multiple roots and canals in human Mandibular premolars. Int Endod J. 1992 Sep;25(5):2347. Pubmed PMID: 1291519

[21]. Trope M, Elfenbein I, Tronstad L. Mandibular premolars with more than one root canal in different race groups. J Endod. 1986 Aug;12(8):343-5. Pubmed PMID: 3462297.

[22]. Sert S, Bayirli GS. Evaluation of the root canal configurations of the mandibular and maxillary permanent teeth by gender in the Turkish population. J Endod. 2004 Jun 1;30(6):391-8.

[23]. Cleghorn BM, Christie WH, Dong CC. The root and root canal morphology of the human mandibular second premolar: a literature review. J Endod. 2007 Sep;33(9):1031-7. Pubmed PMID: 17931927.

[24]. Tzanetakis GN, Lagoudakos TA, Kontakiotis EG. Endodontic treatment of a mandibular second premolar with four canals using operating microscope. J Endod. 2007 Mar;33(3):318-21. Pubmed PMID: 17320724. 